\title{
Activity Reduction of ${ }^{232} \mathrm{Th}$ and ${ }^{40} \mathrm{~K}$ from Simulated Underground Water Using a Clay- Based Membrane
}

\author{
Muazu Abubakar ${ }^{1, *}$ and Norhayati Ahmad $^{2}$ \\ ${ }^{1}$ Department of Mechanical Engineering, Bayero University Kano, PMB 3011 Nigeria \\ ${ }^{2}$ Faculty of Mechanical Engineering, Universiti Teknologi Malaysia, Johor Bahru, Malaysia
}

\begin{abstract}
In this research, the activities of ${ }^{232} \mathrm{Th}$ and ${ }^{40} \mathrm{~K}$ in simulated underground water were reduced using inexpensive clay-based membrane. Starch (10 and $15 \mathrm{wt} \%$ ) was added to the clay, compacted and fired up to $1300^{\circ} \mathrm{C}$ to produce the porous membranes. The characterization of the raw clay and the produced membranes was conducted using XRF, XRD, TGA/DTA, BET and FESEM. The activities of ${ }^{232} \mathrm{Th}$ and ${ }^{40} \mathrm{~K}$ in the waste and permeated water were counted using gamma spectroscopy. The produced membranes were having pore sizes in the range $39.68-46.10 \mathrm{~nm}$; from the BET isotherm, it shows the membranes produced are mesoporous. Also, the steady flux of the filtered water was found to be in the range $3.83 \times 10^{-7}-1.77 \times 10^{-6} \mathrm{~m}^{3} \mathrm{~m}^{-2} \mathrm{~s}^{-1}$. Activities of thorium and potassium in the permeated water were found to be $4.57-5.61 \mathrm{~Bq} / 1$ and 15.49-25.19 $\mathrm{Bq} / 1$ respectively. This shows that inexpensive clay can be used to reduce the activities of thorium and potassium in underground water from mining, fracking and produced water from oil and gas.
\end{abstract}

\section{Introduction}

Anthropogenic activities such as fracking, mining oil and gas exploration have increased the surface water with radionuclides. These radionuclides (uranium, thorium and potassium) are harmful to the organisms living on this environment. Radionuclides are known to cause kidney failures to humans. Some radionuclides are reported to be more toxic chemically than the radiation toxicity [1].

Due to limitations of polymer membranes in terms of chemical, mechanical and thermal resistances and high expensive nature of engineering ceramics such as alumina, titania, zirconia etc., some researchers have resorted in using clay as a starting material in the production of ceramic membranes. Clay minerals are cheap source of ceramic materials such as mullite, which can be obtained by firing the clay at the appropriate temperature.

Several researchers have reported the used of clay based membranes in the removal of heavy metals and radionuclides from wastewater. Jana et al., [2] used clay to produce a membrane for microfiltration for the removal of chromium ion from water and complete removal of chromium ion was achieved. In another research, Ghosh et al., [3] studied the

*Corresponding author: amuazu.mec@buk.edu.ng 
treatment of water containing fluoride, the results indicated a removal of the fluoride ions. In addition, chromium (VI) ions were removed from wastewater using a membrane produced from clay and achieved a reduction of 94\% [4]. Microfiltration and ultrafiltration membrane applications have been used for removal of dye and salt from water and a rejection in the range of 87-95\% was reported. [5]. Lastly, Abubakar et al., [6] reported that ceramic membrane from clay was used in the activity reduction of uranium in simulated underground water and a rejection of $96.6 \%$ was reported.

The dead end filtration module has the limitation of retaining particles/deposits on the surface of the membrane and inside the membrane. As a result, the particles deposited on the membrane surface cause an increased resistance to the filtered water flux, thus causing a flux decline with time [7].

Though dead end module has the limitation of fouling and small surface area for membrane filtration, this filtration module is less expensive and easy to fabricate, which reduces the cost of production compared with tubular, spiral wound and hollow fibre modules. Dead-end modules are the simplest modules, which are produced with an average diameter $50 \mathrm{~mm}$ diameter and $5 \mathrm{~mm}$ thickness $[2,8]$. As many researchers reported the removal of heavy metals and some radionuclides from wastewater using ceramic membrane from clay, however, there is no study on the use of clay-based membrane for the removal of thorium and potassium from wastewater.

The objective of this study is to characterize local clay and fabricate membranes with different starch compositions (10 and $15 \mathrm{wt} \%)$. The membranes produced were tested for the reduction in activity of thorium and potassium in wastewater.

\section{Materials and Methods}

\subsection{Material characterization}

The clay used in this study was locally sourced from Kankara, Nigeria. The oxides composition of the clay sample was determined by X-ray fluorescence spectroscopy (Philips PW 2400 spectrometer). The clay was ground to reduce the lumps into fine powders and screened through a $50 \mu \mathrm{m}$ sieve. Thermogravimetric and differential thermal analysis (TGA/DTA) of the clay was performed using a PerkinElmer from $50^{\circ} \mathrm{C}$ up to a temperature of $1100^{\circ} \mathrm{C}$. XRD was performed on both the raw and fired clay at $1300^{\circ} \mathrm{C}$. The morphology analysis of the clay was conducted using field emission scanning electron microscopy (FESEM, Gemini SupraTM 35vp).

\subsection{Membrane preparation and characterization}

The cassava starch at different percentages (10 and $15 \mathrm{wt} \%$ ) was added to the clay and wet mixing was conducted using ethanol; the mixture was milled using alumina balls for $4 \mathrm{~h}$, calcined in an oven for $24 \mathrm{~h}$ and compacted using an INSTRON 600DX machine into circular discs samples of average dimension $30 \times 4 \mathrm{~cm}$ at a pressure of $60 \mathrm{MPa}$. The firing of the compacts was performed at $1300^{\circ} \mathrm{C}$ for $2 \mathrm{~h}$. The microstructures of the fractured surface of the clay-based membranes were recorded using FESEM after sputtering with gold. The pore properties of the samples were determined by BET multipoint measurements on a TriStar II 3020 surface area and porosity analyzer with $\mathrm{N} 2$ adsorbate at $-196^{\circ} \mathrm{C}$ for $4 \mathrm{~h}$ under vacuum conditions. 


\subsection{Filtration test}

The ceramic membranes produced from clay were tested for the removal of thorium and potassium radionuclides from wastewater. The stimulated wastewater was prepared using $12 \mathrm{~L}$ double-distilled water and $100 \mathrm{~g}$ standard reference thorium and potassium ore (IAEA-RGTh-1 and IAEA-RGK-1). The filtration process conducted at 3 bar transmembrane pressure at average an flow rate of $2 \mathrm{~L} / \mathrm{min}$. The wastewater and the filtered water were packed in sealed $500 \mathrm{ml}$ Marinelli beakers. The samples were stored for a period of four weeks to attain a natural equilibrium. Activities of thorium and potassium in the waste and the filtered water were measured using gamma spectroscopy with a coaxial germanium detector (GC2018-7500 SL). The filtered water flux was calculated for all of the ceramic membranes. The filtered water flux $\mathrm{J}$ was calculated using Eq. 1 [3]:

$$
J=\frac{Q_{w}}{A \Delta t}
$$

where $Q_{w}$ is the filtered water volume (m3), A is the membrane effective area $(\mathrm{m} 2)$, and $\Delta \mathrm{t}$ is the filtration time.

\section{Results and Discussion}

\subsection{Characterization of raw material}

The XRF analysis Table 1 of the clay sieved through $50 \mu \mathrm{m}$ shows that silica and alumina have the highest concentration in the clay. Other compounds are due to impurities that are normally attached to clay.

\begin{tabular}{|l|l|}
\hline Compound & Concentration \\
\hline $\mathrm{SiO} 2$ & 55.4 \\
\hline $\mathrm{AL} 2 \mathrm{O} 3$ & 42.9 \\
\hline $\mathrm{K} 2 \mathrm{O}$ & 1.3 \\
\hline $\mathrm{FE} 2 \mathrm{O} 3$ & 0.3 \\
\hline $\mathrm{CaO}$ & 0.06 \\
\hline $\mathrm{TiO} 2$ & 0.05 \\
\hline $\mathrm{MgO}$ & 0.04 \\
\hline $\mathrm{MnO}$ & 0.03 \\
\hline
\end{tabular}

Table 1: Chemical composition of raw clay

In addition, the microstructure of the raw clay sieved through $50 \mu \mathrm{m}$ (Fig. 1) shows the presence of an accordion type of structures in the form of books, which is a typical microstructure of kaolin clay. 


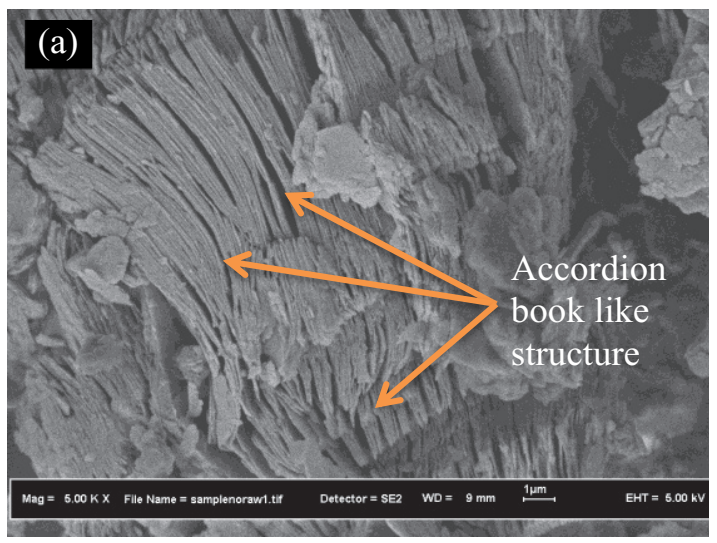

Fig. 1: Microstructure of raw clay

The X-ray diffraction analysis in Fig. 2 revealed sharp peaks of kaolinite phase with some peaks of quartz and illite phases. The clay shows a distinct kaolinite peaks at 2 theta of $12.34^{\circ}, 19.75^{\circ}, 24.64^{\circ}$ and $38.35^{\circ}$, which correspond to a d value of $7.154,3.59,2.34$ and $1.49 \AA$ respectively with a plane reflection of $(001)$. However, that of quartz and illite $\mathrm{d}$ values occurs at $3.35 \AA$ and $10.08 \AA$ at plane reflections of (101) and (001) respectively. These are some lattice characteristics of the kaolinite clay, as reported by [9]. The phase transformation of the clay at firing temperature of $1300^{\circ} \mathrm{C}$ (Fig. 2) shows the existence of the base-centred monoclinic mullite phase.

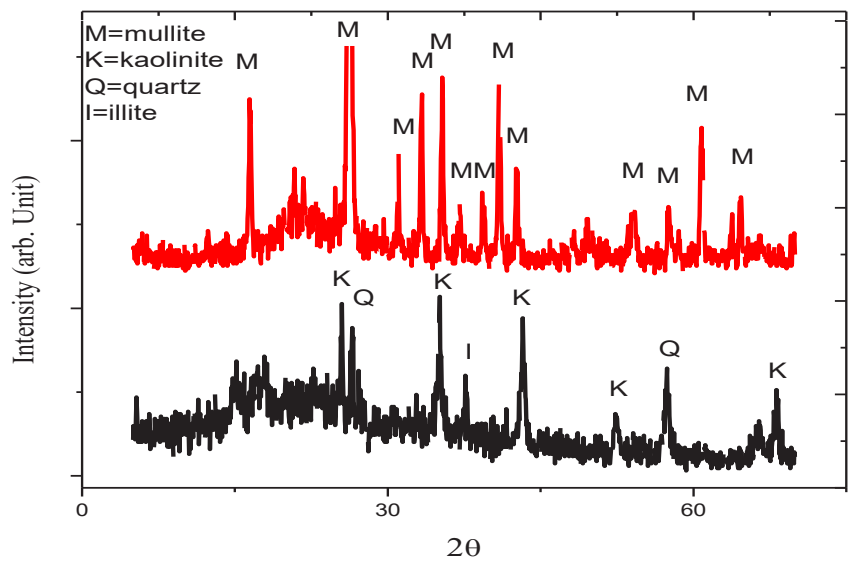

Fig. 2: XRD analysis of raw and sintered clay at $1300^{\circ} \mathrm{C}$

Fig. 3 shows the thermal decomposition of the clay with temperature. From the figure, the total loss on ignition of the clay is approximately $11.09 \%$ due to removal of both physical and chemical combined water and conversion of kaolin to metakaolin. The DTA curve shows an endothermic peak at a temperature of $485^{\circ} \mathrm{C}$; this is as a result of the conversion of kaolin to metakaolin and removal of water of crystallization. The second, an exothermic peak at a temperature of $960^{\circ} \mathrm{C}$; this is due to conversion of metakaolin to spinel, which later transforms to mullite after heating to a temperature of $1100^{\circ} \mathrm{c}$. 


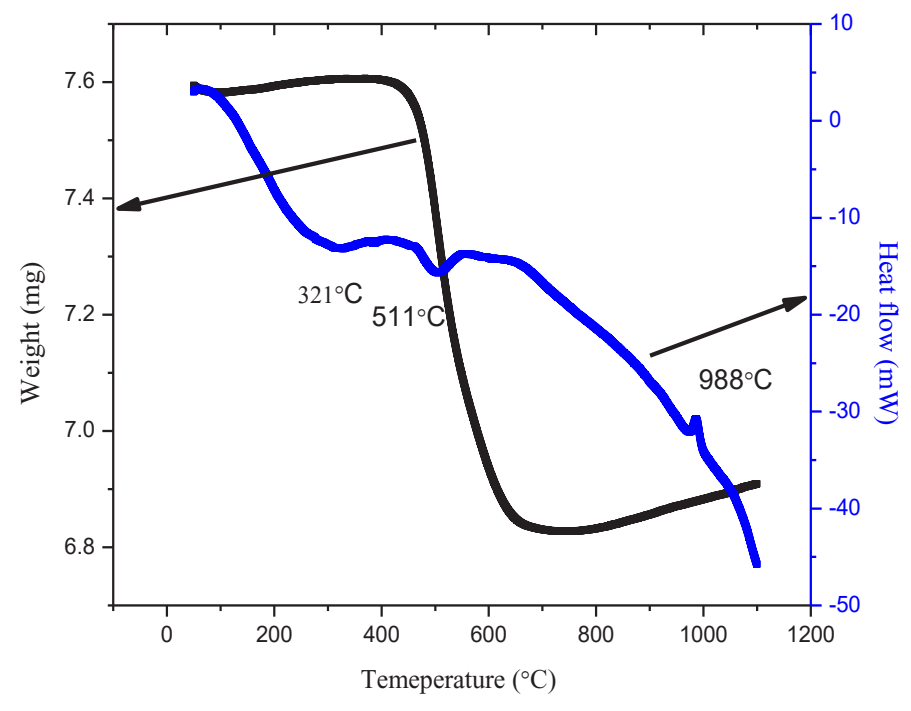

Fig. 3: Thermal analysis of clay

\subsection{Membrane Properties}

The microstructure of the porous fired clay with 10 and $15 \mathrm{wt} \%$ starch (Fig. 4) shows that porosity increases with increase in percentage starch and the pores formed are of slit shape, as shown by the adsorption/desorption isotherm (Fig. 5). The increase of the starch in the ceramic products increases the density of porosity after firing.

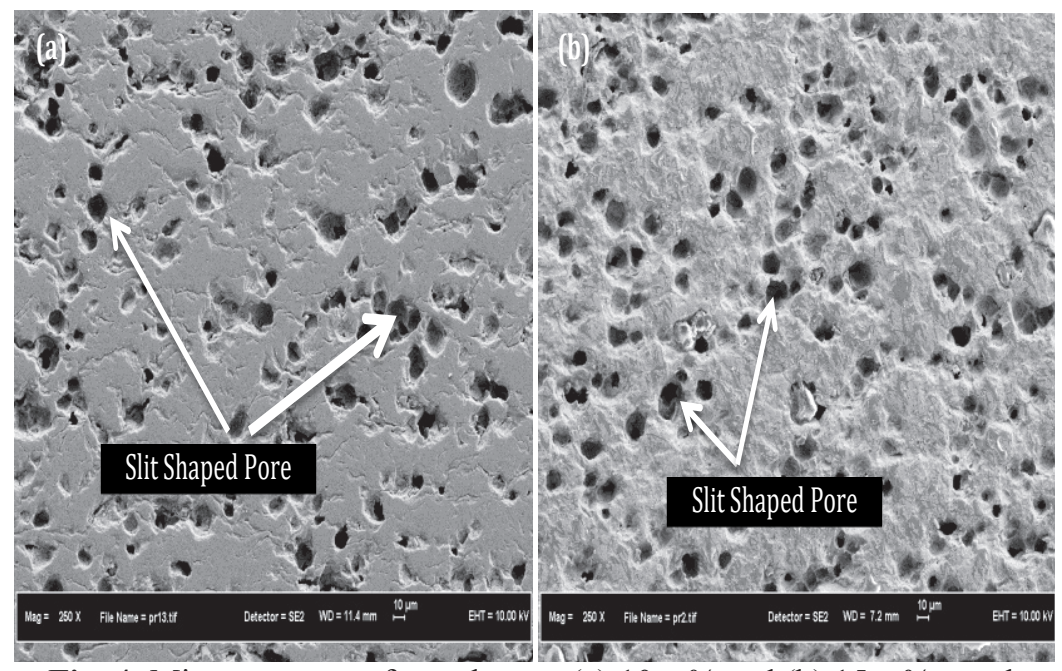

Fig. 4: Microstructure of membranes (a) $10 \mathrm{wt} \%$ and (b) $15 \mathrm{wt} \%$ starch

The adsorption/desorption isotherm obtained from the BET data of the porous ceramics with 10 and $15 \mathrm{wt} \%$ starch addition are shown in Fig 5. The adsorption/desorption isotherms of the 10 and $15 \mathrm{wt} \%$ starch show an initial increase in the adsorption isotherm due to monolayer formation and a slope region in the middle due to formation of first multilayer, followed by a capillary condensation due to high increase at the adsorption 
branch of the isotherm at a relative pressure above 0.9 , which further proves the presence of mesopores. The isotherm presents a step down in the desorption branch, with the adsorption branch of the isotherm lying below the desorption branch. According to IUPAC standards for the identification of porous materials, this behavior type is of type IV isotherm with H3 type hysteresis for all the porous ceramics produced. Presence of hysteresis of type H3 proved that the porous ceramics are mesoporous of slit-shaped pores. During the desorption process the isotherm closed at a relative pressure close to 0.1 , which indicates a relative distribution of slit-shaped pores. The ceramics with $15 \mathrm{wt} \%$ starch shows higher adsorption/desorption isotherm due the presence of more pores compared with ceramic with $10 \mathrm{wt} \%$ starch. This is also supported by Fig. 4.

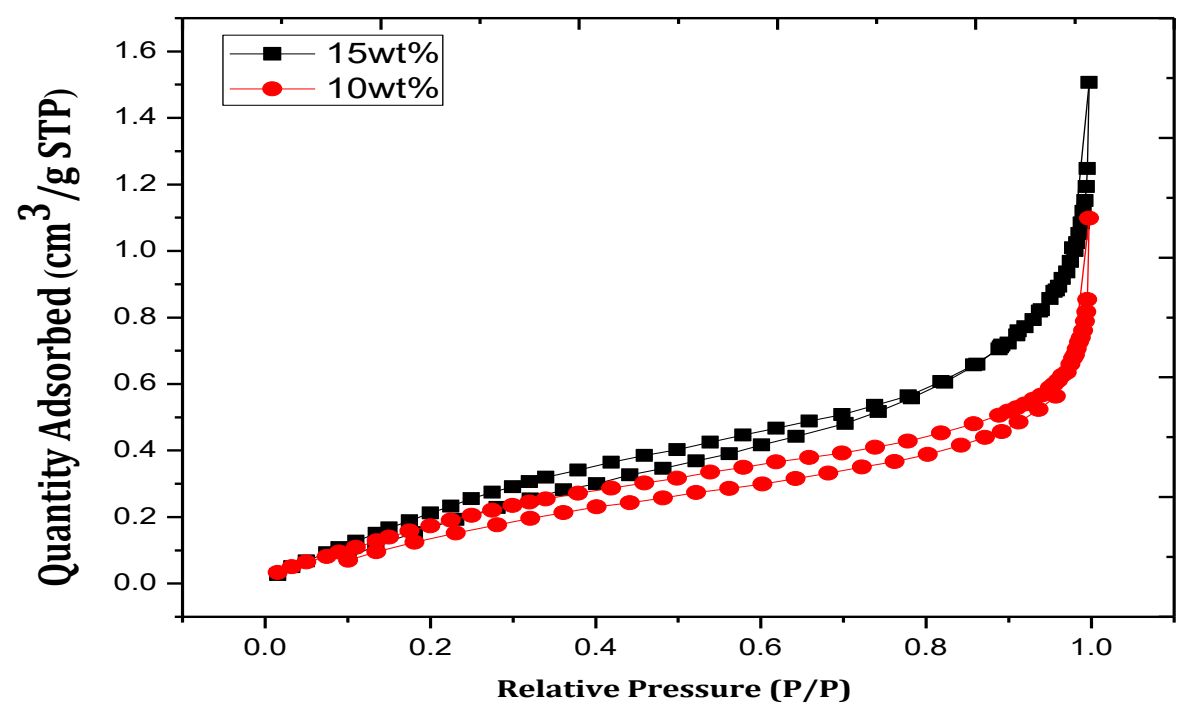

Fig. 5: Adsorption/desorption isotherm of membranes

The pore size distribution (Fig. 6) shows all the porous ceramics contain a main sharp peak at approximately $20.00 \mathrm{~nm}$, which are highly uniform in structure; other peaks are termed artificial peaks, which also contribute to the final thickness of the pores [10]. The average pore size of the porous ceramics with 10 and $15 \mathrm{wt} \%$ starch are found to be 39.68 , 46.10 and $55.13 \mathrm{~nm}$ respectively, this further proves the porous ceramics are mesoporous. The BET specific surface area of the porous ceramics membranes (10 and 15wt\% starch addition) were found to be 1.60 and $2.11 \mathrm{~m} 2 / \mathrm{g}$ respectively. This variation shows an increase with increase in starch content, which result in porosity increase as percentage starch increases. 


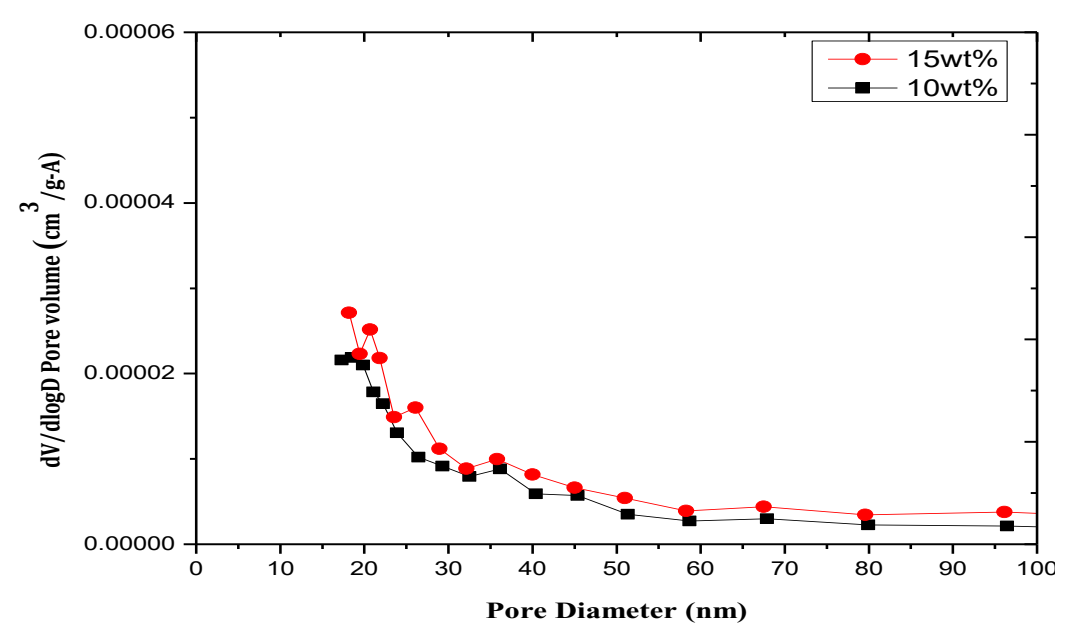

Fig. 6: Pore size distribution of membranes

\subsection{Membrane filtration and water quality}

Fig. 7 shows the filtered water flux profile after every minute at a 3 bar trans-membrane pressure with a flow rate of $21 / \mathrm{min}$ and a filtration time of $30 \mathrm{~min}$ for the membranes containing 10 and $15 \mathrm{wt} \%$ starch. From the figure, it shows that the filtered water flux decreases with for the 10 and $15 \mathrm{wt} \%$ starch membranes. For the $10 \mathrm{wt} \% \%$ starch membrane, the filtered water flux decreases from $1.59 \mathrm{E}-05 \mathrm{~m} 3 \mathrm{~m}-2 \mathrm{~s}-1$ to a steady state of $3.83 \mathrm{E}-06$ $\mathrm{m} 3 \mathrm{~m}-2 \mathrm{~s}-1$ while for the $15 \mathrm{wt} . \%$ starch membrane, the filtered water flux decline from $5,60 \mathrm{E}-04 \mathrm{~m} 3 \mathrm{~m}-2 \mathrm{~s}-1$ to a steady state of $1.77 \mathrm{E}-05 \mathrm{~m} 3 \mathrm{~m}-2 \mathrm{~s}-1$. The initial filtered water flux decline with time can be attributed to two phenomenon. The first is due to particles deposition inside the membrane pores, which decreases the filtered water flux. This phenomenon is known as fouling. For the second, as the filtration time increases, some particles deposited on the membrane surface and this further increases the membrane resistance, a phenomenon called "concentration polarization". In the first stage of the decline (membrane fouling) was very fast, and then as filtration time increases, a steady state flux is achieved [2]. Furthermore, the initial and the final filtered water fluxes show an increase with as the percentage of the starch increases for all the porous membranes (10 and $15 \mathrm{wt} \%)$. The amount of the filtered water flux depends on the porosity. Higher porosity resulted to higher filtered water flux. 


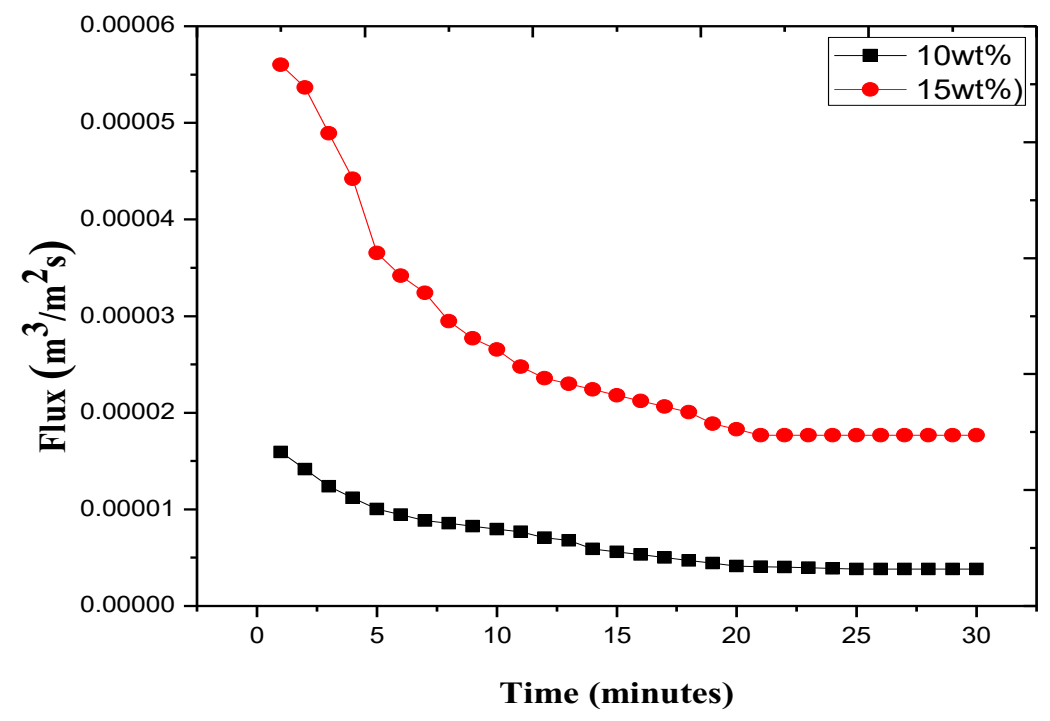

Fig. 7: Permeate flux decline of membranes

The activities of $232 \mathrm{Th}$ and $40 \mathrm{~K}$ in the feed and filtered water for the 10 and $15 \mathrm{wt} \%$ starch membranes counted using gamma spectroscopy show that the activities of $232 \mathrm{Th}$ and $40 \mathrm{~K}$ in the waste water are high, with activities of 33.30 and $34.52 \mathrm{~Bq} \mathrm{1-1}$ respectively. The activities of $232 \mathrm{Th}$ and $40 \mathrm{~K}$ in the filtered water show an increase from 10 to $15 \mathrm{wt} \%$ starch content. The wastewater filtered through the porous membrane with $10 \mathrm{wt} \% \mathrm{starch}$ gives $232 \mathrm{Th}$ and $40 \mathrm{~K}$ activities of 4.57 and 5.61 respectively, while $15 \mathrm{wt} \%$ gives $232 \mathrm{Th}$ and $40 \mathrm{~K}$ activities of 15.49 and $25.19 \mathrm{~Bq} \mathrm{1-1}$, respectively. The activities of $232 \mathrm{Th}$ and $40 \mathrm{~K}$ increases with starch addition. The increase of the starch addition from 10 to $15 \mathrm{wt} \%$ resulted in the increases in the amount of pores after firing. Therefore, the $232 \mathrm{Th}$ and $40 \mathrm{~K}$ activities increase with the increase in starch addition. The membranes produced can be applied to treat underground wastewater containing $232 \mathrm{Th}$ and $40 \mathrm{~K}$ mining and, oil drilling, which produce wastewater with high technologically enhanced, naturally occurring radionuclide materials (TENORM).

\section{Conclusion}

Based on the results, kaolin clay can be used to fabricate a porous membrane for the treatment of $232 \mathrm{Th}$ and $40 \mathrm{~K}$ from underground water. In addition, the membranes produced are mesoporous with slit-shaped pores. The filtered water flux decreases with increase in filtration time. However the filtered water flux increases with increase in starch addition. Rejection of $232 \mathrm{Th}$ and $40 \mathrm{~K}$ decreases with increase in starch addition.

\section{Acknowledgement}

Special thanks go to Universiti Teknologi Malaysia and Bayero University Kano through Tertiary Education Training Fund (TETFund) for sponsorship. 


\section{References}

1. USEPA, Use of uranium drinking water standards under 40 CFR 141 and 40 CFR 192 as goals sremediation for groundwater at CERCLA sites, (2001).

2. S. Jana, M.K. Purkait, K. Mohanty, Preparation and characterization of low-cost ceramic microfiltration membranes for the removal of chromate from aqueous solutions. Applied Clay Science, 47, 317-324. (2010)

3. D. Ghosh, M.K. Sinha, M.K. Purkait, A comparative analysis of low-cost ceramic membrane preparation for effective fluoride removal using hybrid technique. Desalination, 327, 2-13. (2013)

4. D. Vasanth, G. Pugazhenthi, R Uppaluri, Biomass assisted microfiltration of chromium(VI) using Baker's yeast by ceramic membrane prepared from low cost raw materials. Desalination, 285, 239-244. (2012)

5. N. Saffaj, M. Persin, S.A. Younsi, A. Albizane, M. Cretin, A. Larbot, Elaboration and characterization of microfiltration and ultrafiltration membranes deposited on raw support prepared from natural Moroccan clay: Application to filtration of solution containing dyes and salts. Applied Clay Science, 31, 110-119. (2006)

6. M. Abubakar, M.N. Tamin, M.A. Saleh, M.B. Uday, N. Ahmad, Preparation and characterization of a nigerian mesoporous clay-based membrane for uranium removal from underground water. Ceramics International, 42, 8212-8220. (2016)

7. S. Banerjee, S. Mondal, De, S. Gel controlling dead-end membrane filtration: Theory revisited. Separation and Purification Technology, 99, 77-85. (2012)

8. H. Al-Hammadi, N. Al-Bastaki, Experimental study of the dead-end ultrafiltration process using silicone dioxide suspensions. Desalination, 206, 513-523. (2007)

9. M. Gougazeh, J.-C. Buhl, Synthesis and characterization of zeolite A by hydrothermal transformation of natural Jordanian kaolin. Journal of the Association of Arab Universities for Basic and Applied Sciences, 15, 35-42. University of Bahrain. (2014)

10. J. Fu, Q. He, B. Liu, J. Zhang, B. Hu, Study in adsorption behavior of polymer on molecular sieves by surface and pore properties. Colloids and Surfaces A: Physicochemical and Engineering Aspects, 369, 113-120. (2010) 